\title{
Evaluation of Tourism Development Potential on Provinces along the Belt and Road in China: Generation of a Comprehensive Index System
}

\author{
Yuying Chen ${ }^{1,2,3}$, Yajie $\mathrm{Li}^{2}$, Xiangfeng $\mathrm{Gu}^{4}{ }^{\text {, Nan Chen }}{ }^{1,2,3\left(\mathbb{D}, \text { Qing Yuan }{ }^{1,2,5, *(\mathbb{C})} \text { and Ming Yan }\right.}{ }^{6}$ \\ 1 Research Institute of Study Travel, Henan University, Kaifeng 475001, China; yychndx@henu.edu.cn (Y.C.); \\ 10020053@vip.henu.edu.cn (N.C.) \\ 2 School of Cultural Industry \& Tourism Management, Henan University, Kaifeng 475001, China; \\ 1710021120@vip.henu.edu.cn \\ 3 Research Institute for the Yellow River National Cultural Park, Henan University, Kaifeng 475001, China \\ 4 Faculty of Geographical Science, Beijing Normal University, Beijing 100875, China; \\ 201911051110@mail.bnu.edu.cn \\ 5 College of Geography and Environmental Science, Henan University, Kaifeng 475004, China \\ 6 Institute of Employment Entrepreneurship Guidance, Henan University of Economics and Law, \\ Zhengzhou 450046, China; yanming0131@126.com \\ * Correspondence: yuanqing@henu.edu.cn; Tel.: +86-185-3946-6548
}

check for updates

Citation: Chen, Y.; Li, Y.; Gu, X.; Chen, N.; Yuan, Q.; Yan, M.

Evaluation of Tourism Development Potential on Provinces along the Belt and Road in China: Generation of a Comprehensive Index System. Land 2021, 10, 905. https://doi.org/ 10.3390/land10090905

Academic Editor: Alastair M Morrison

Received: 11 July 2021

Accepted: 24 August 2021

Published: 27 August 2021

Publisher's Note: MDPI stays neutral with regard to jurisdictional claims in published maps and institutional affiliations.

Copyright: (c) 2021 by the authors. Licensee MDPI, Basel, Switzerland This article is an open access article distributed under the terms and conditions of the Creative Commons Attribution (CC BY) license (https:// creativecommons.org/licenses/by/ $4.0 /$ )

\begin{abstract}
The evaluation of tourism development potential (TDP) is the crucial foundation and critical step for sustainable regional tourism development. Prior studies mainly evaluate TDP through the univariate potential model and the multi-indicator descriptive evaluation. However, these two methods have only limited effectiveness for the destination's TDP in the context of the mesoscale level. Thus, this study aims to develop an effective multi-dimensional mesoscale to evaluate the destination's TDP and construct a potential index model. Based on the literature review, this study develops four rule layers (tourism supply and consumption $\left(X_{1}\right)$, the demand and purchasing power of tourist source $\left(X_{2}\right)$, development value of destination resources $\left(X_{3}\right)$, and the contribution of the destination's tourism industry $\left(X_{4}\right)$ ) and 31 factor layers. All the factor layers are then assigned values based on the provincial statistics in China in 2019. Through SPSS 24.0, the current study uses the principal component analysis (PCA) to construct a provincial TDP index model for the research area: $Y=0.2573 X_{1}+0.1305 X_{2}+0.3177 X_{3}+0.2945 X_{4}$. The results show significant regional differences in the TDP index of the provinces along the Belt and Road (study area) in China. Among them, Guangdong has the most extensive TDP index, Qinghai has the smallest TDP index. The study also uses ArcGIS 10.2 for the function of kernel density analysis to visualize provincial TDP and finds significant spatial differences and a central-edge distribution pattern across provinces.
\end{abstract}

Keywords: tourism development potential; principal component analysis; Belt and Road along with China; provincial tourism destination

\section{Introduction}

More than 2000 years ago, the people of Asia, Europe, and Africa jointly opened up several economic and cultural exchange channels connecting the three continents, called the Silk Road by later generations. For thousands of years, the Silk Road spirit of "peace and cooperation, openness and inclusiveness, mutual learning and mutual benefit" has been passed from generation to generation, forming an essential link for the prosperity and development of society and economy in all regions along the route. In the 21st century, in the new era with the theme of "peace, development, cooperation, and mutual benefit", the spirit of the Silk Road is inherited and promoted. In 2013, during a visit to Central and Southeast Asian countries, Chinese President Xi Jinping proposed building the Silk Road Economic Belt and the 21st Century Maritime Silk Road (hereinafter referred to as 
the Belt and Road). The Belt and Road strategy proposed by the Chinese government aims to promote the orderly and free flow of economic elements, the efficient allocation of resources, and the deep integration of markets to achieve coordinated, open, inclusive, and sustainable development. The strategy also suggests the countries along the Belt and Road to strengthen tourism cooperation, expand the scale of tourism industry, organize tourism promotion activities, and improve the level of visa facilitation for tourists from countries along the route [1]. The Belt and Road plan covers the continents of Europe, Asia, and Africa. The provinces involved in the route along China include Shaanxi, Gansu, Heilongjiang, Guangdong, Yunnan, Shanghai, Fujian, and Hong Kong, Macao, Taiwan regions. City clusters along the middle reach of the Yangtze River, around the regions of Chengdu and Chongqing, and the regions of central Henan province are also included. Building tourism hub cities, promoting the alliance of the tourism industry in the regions along the route, and realizing the interconnection of facilities and the sustainability of tourism development have gradually become important goals of the cities along the Belt and Road [2,3]. In the context of this, more and more Chinese provinces along the Belt and Road have begun to attach importance to the strategic significance and sustainability of tourism development to seize this potential international development opportunity.

Prior studies related to the Belt and Road mainly focus on the meaning, concept, mechanism, difficulties and challenges, policy, and the level and progress of interconnection [4-8]. However, attention to the tourism development potential (TDP) in the regions along the route is still lacking. The evaluation of TDP is an important basis for destination management and decision-making, which can help local governments decide how to allocate and optimize resources for sustainable tourism development. Among the countries along the Belt and Road, China's tourism development is representative. In the context of China's high economic growth, the tourism industry in China has developed rapidly. However, due to regional differences in resource endowments, business philosophy, investment and financing capabilities, policy institution and other conditions, the tourism development status and development potential of the provinces along the Belt and Road in China are all heterogeneous. Therefore, it is very necessary to accurately evaluate the TDP of each province to promote the provincial tourism cooperation and sustainable development.

The evaluation of development potential considers the region's element resources and market size, and the impact from other regions, reflecting the development opportunities that the region may have in larger regional systems [9]. For the sustainable development of tourist destinations, the tourism development potential assessed by multiple indicators is necessary. It is the basis for guiding tourists to choose the most exciting destinations [10], which can improve the market positioning of the source country [11], helps tourism managers and operators to develop a reasonable tourism plan [12], effectively enhances tourism attractiveness, increases the alternative source of income for rural residents, and ensures the sustainable development of rural areas [13].

Over the years, researchers have been working to determine the TDP, but the research methods are still very different. Based on combing the relevant literature of TDP evaluation, this study tries to integrate technical evaluation and comprehensive evaluation approaches to identify the rules and factors of the destination's TDP index. Furthermore, this study also tries to optimize the index system of destination TDP evaluation and construct a potential index model through principal component analysis, make comprehensive measurement of TDP along the Belt and Road in China, and put forward policy recommendations for its sustainable development. Following this research idea, this study will be composed of five parts: introduction, literature review, research methods, results, discussions and conclusions.

\section{Literature Review}

\subsection{Tourism Development Potential (TDP)}

TDP is an assessment path to predict the sustainable development of tourism [14], beneficial to the multi-attribute decision-making of tourist destinations [15]. The TDP in a region or country has always been a hot topic in tourism research. Initially, tourism poten- 
tial was seen as an element in meeting the complex needs of tourists [16]. By the 1990s, the tourism potential was widely used in the economic and geographical fields and gradually became material and non-material collection capable of promoting tourism capitalization and fully demonstrating its function [17-19]. Furthermore, the concept of TDP has been further assigned to the social and environmental elements of tourist destinations [20,21]. Later, most of the discussion on the concept and connotation of TDP is based on sustainable development. Ma and Dong considered that the potential for sustainable development of regional tourism refers to the total supply limits reached by regional environments, socio-economic support, and tourism resources over a given period [22]. Yang found that the potential of regional tourism development is the ability to promote the sustainable development of tourism in tourism development stimulated by certain elements [23]. Wang combined the research paradigm of geography to emphasize that the TDP is the space for sustainable development of tourism under tourism resources, social economy, and environmental capacity. It is a critical element in measuring regional tourism development and a comprehensive measure of the sustainable development prospects of regional tourism [24]. Based on the multidisciplinary perspectives of geography, economics, and management, and in the context of spatial scale and sustainable development of tourist destinations, this study holds that the TDP is the exchange and transformation ability of the complex system of destination resources, society, economy, and technology, and the driving force of sustainable development. It is manifested in the value of tourism resources, the expansion of the source market, the attraction of tourism, economic support, the consumption of tourism development, the spatial role of tourist flow, etc.

TDP has an essential impact on the tourism competitiveness and sustainable development of destinations, especially on the sustainable development of goal-setting, the determination of critical elements, the constraints and forms of the formation process [25,26]. Prior studies have shown that technology potential and resource development potential are essential in evaluating the destination's TDP $[27,28]$. Regarding how to evaluate the TDP, studies focused mainly on three approaches: experiential evaluation, technical evaluation, and comprehensive evaluation. The evaluation methods mainly include: (a) using entropy weight method, standard deviation method, multilinear regression method to quantify tourist reception; (b) using matrix form to assign indicators to reveal the importance of indicators; (c) using geographic information system (GIS) to assess the TDP; (d) the application of multi-criteria decision-making technology [20]. While there are also studies exploring market-driven indicator evaluation systems from the supply side to the demand side, more information on the development of tourist destinations is a central prerequisite for evaluating TDP [29]. Therefore, based on a multi-dimensional and comprehensive evaluation index system through more tourism destination development information, this study discusses the comprehensive evaluation index system and establishes a TDP model in the research area. Furthermore, based on the results of prior studies, the current study argued that destination TDP is the development ability, the market share of customer sources, product competition ability of the source market, and the sustainable ability to develop tourism destination. Accurately analyzing and evaluating the TDP can help find the future growth space and sustainable development direction of tourism destinations. Therefore, this study proposes a cognitive model of a comprehensive evaluation index system through inductive deduction to better understand the necessary elements in evaluating the destination's TDP. As shown in Figure 1, the model provides a macro approach to determine the TDP of the major provincial units along China's Belt and Road and serves its strategic decision-making on sustainable tourism development.

\subsection{Evaluation Index System}

TDP is an integrated development capacity to achieve sustainable development [29], which is susceptible to the dual factors of tourism demand and tourism supply. Some scholars explore the tourism development factors with high value and high contribution through Delphi or questionnaire method and construct the evaluation index system of 
TDP [30,31]. Some scholars also identify the connotation and extension of TDP to develop qualitative or quantitative research methods and build comprehensive index [32].

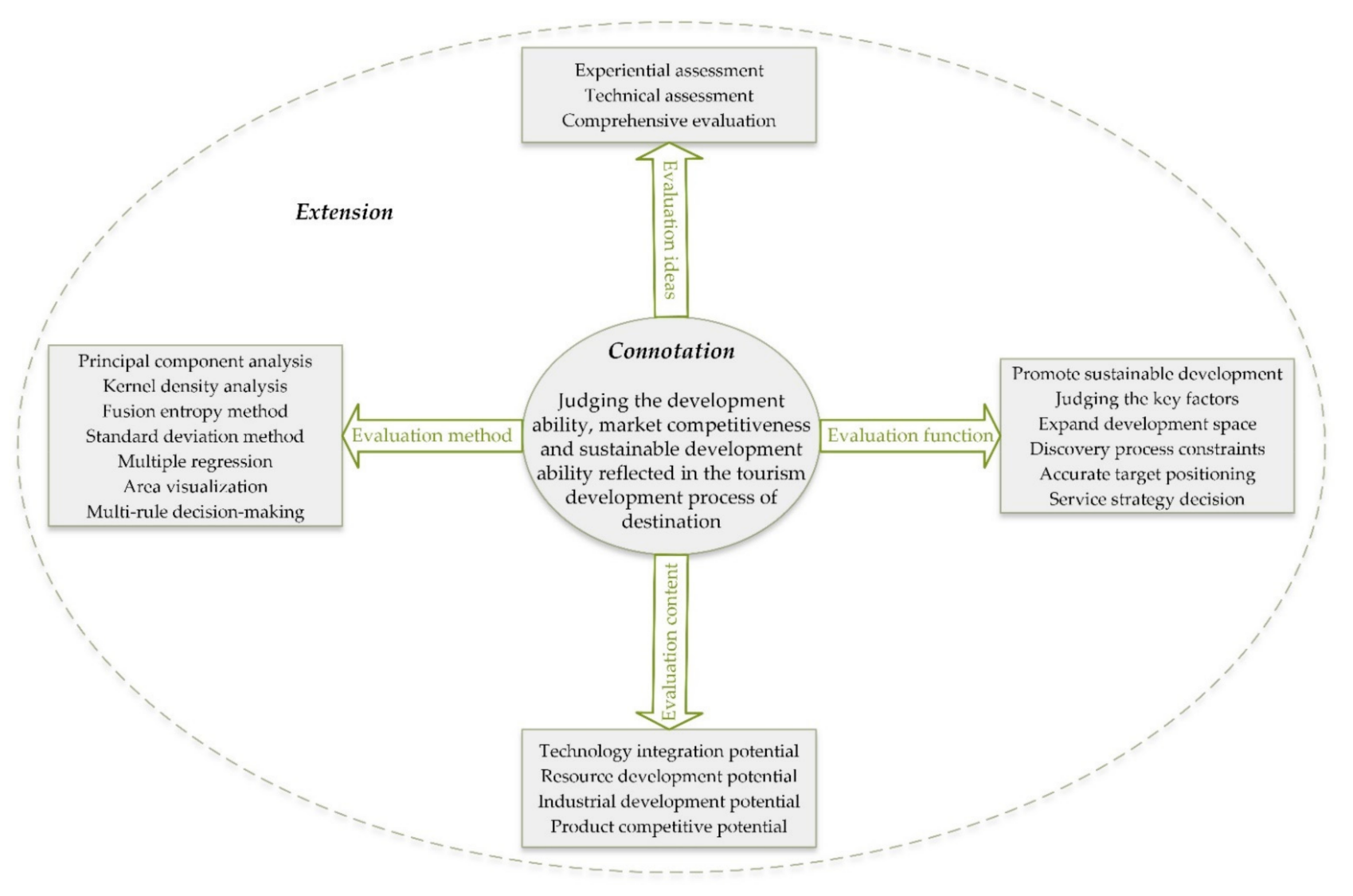

Figure 1. Conceptual cognitive model for evaluation of Destination TDP.

The TDP is also affected by the potential of the tourism industry and the potential of tourism support. The potential of the tourism industry is the internal and leading factor of the TDP [33]. As the TDP is a concept with both openness and comprehensiveness, the construction of the evaluation index system of regional TDP should be diversified. In the context of this, there are multiple evaluation index systems in the relevant study on the development potential of China's provincial tourism industry. For example, four rule layers with fifty-eight-factor layers including tourism demand capacity, tourism supply capacity, tourism potential guarantee, and tourism potential support [34]; three rule layers with multiple factor layers including the driving force of the elements of the tourism industry, the driving force of tourism market demand and the support of tourism industry environment [35]; five rule layers with thirty-six-factor layers including tourism market supply, regional comprehensive strength, ecological environment, economic foundation, innovation in science, education, and culture [36]; five rule layers with twenty-eightfactor layers including comprehensive economic strength, tourism development level, infrastructure, ecological environment, science and education hygiene [37]. Ding \& Zhu believed that the development potential of the regional tourism industry refers to the ability to stimulate the transformation of other elements related to the tourism industry in the region, promotes and supports the sustainable development of the tourism industry by improving the underuse or overuse of its existing production elements, and describes the potential dynamics for future development [38]. Yu emphasized that the sustainability of the development potential of the regional tourism industry is affected by its internal and external environment. It includes the tourism industry's internal elements and the primary support elements, institutional support elements, environmental protection elements, and 
other external environment related to the tourism industry and its extended industries in the region where the tourism industry is located [39].

Some studies evaluated the development potential of regional tourism based on a product perspective. For example, the evaluation of the rural TDP can be judged by indicators such as accommodation supply, tourism activities, natural environment [40], or by reference to nineteen indicators at the three administrative levels of the region, street and community, such as economic basis, natural and climatic conditions, tourism facilities, and resident's support [13]. Ruda believed that equally weighted systems of natural, cultural, and historical indicators are better suited to evaluating the potential of forest tourism [10]. $\mathrm{Li}$ argued that the evaluation of the TDP of protected areas could refer to three rule layers and twelve-factor layers, such as tourism system footprint, tourism carrying capacity, and system diversity [41]. Wang suggested that the potential of glacier tourism can be evaluated from the location and transportation, resources and environment, development level and market, socio-economic potential, and other aspects of the indicator system [12].

In addition to the tourism as mentioned above, tourism supply, tourism demand, tourism resources, tourism industry, destination areas, and other generally recognized TDP evaluation factors, there are some that are more typical, with regional characteristics of them, such as money, the number of endogenous resources, political policies, and other factors. Currency is an essential factor affecting the TDP. For example, the impact of the euro on the stream of European tourists is very significant, which could even be around $44.6 \%$ [42]. It also affects the potential tourism benefits of the European Monetary Union region, and the financial characteristics of common currency transnational tourism destinations are formed. Furthermore, Jana found that the number of endogenous resources in the Nitra Autonomous Region dominated the regional synergies of tourism development [43]. Masood believed that Iran's tourism development is significantly influenced by political policies, as evidenced by the significant increase in inbound tourists from Western countries and foreign investment in Iran's tourism-related infrastructure following the implementation of the Iran Nuclear Deal [44]. However, Donald Trump's newly aggressive foreign policy toward Iran could challenge the country's international tourism development.

According to the type of influencing factors, the sustainable development potential of regional tourism can be divided into three types: tourism resource potential, regional support potential, and environment carrying capacity potential. These three types of potential can be quantitatively evaluated by exploring the mathematical relationship between tourism resource scale and quality, tourism development conditions, the travel rate of tourism destination, per capita income of tourism destination, tourism multiplier, tourism consumption coefficient, tourism reception volume, and tourism revenue [22] Li developed a TDP index system with five rule layers and twenty-seven-factor layers, including tourism attraction, a resource base for tourism product development, cultural heritage management, the value of cultural tourism resources, and consumption of tourism supply [45]. Feng et al. constructed a system for evaluating the sustainable development potential of tourism destination ecosystems, including twenty-nine-factor layers of four rule layers with supporting entropy input, stress entropy output, consumption entropy metabolism, and regenerative entropy metabolism [46].

Based on the above literature, it can be found that the applied research of potential model in the field of tourism exists in the regional, resource, industry, supply and demand, products, policies, and other diversified differentiated evaluation index system. Regardless of the TDP evaluation index system, the results can guide the sustainable development of regional tourism [47]. The TDP depends on both the resources allocated and the resources established [48], and its evaluation index should be the sum of material and non-material resources, including natural resources, cultural resources, infrastructure and tourism facilities [17], as well as the natural environment, political environment, and socio-economic basis. In summary, the layer for evaluating the regional tourism industry's development potential in existing studies is multi-perspective, multilevel, and pluralistic, and their development structure can be summarized as shown in Figure 2. In this context, the current 
study will combine the characteristics of different potential factors and select an evaluation index based on the needs of the development potential of tourism destinations.

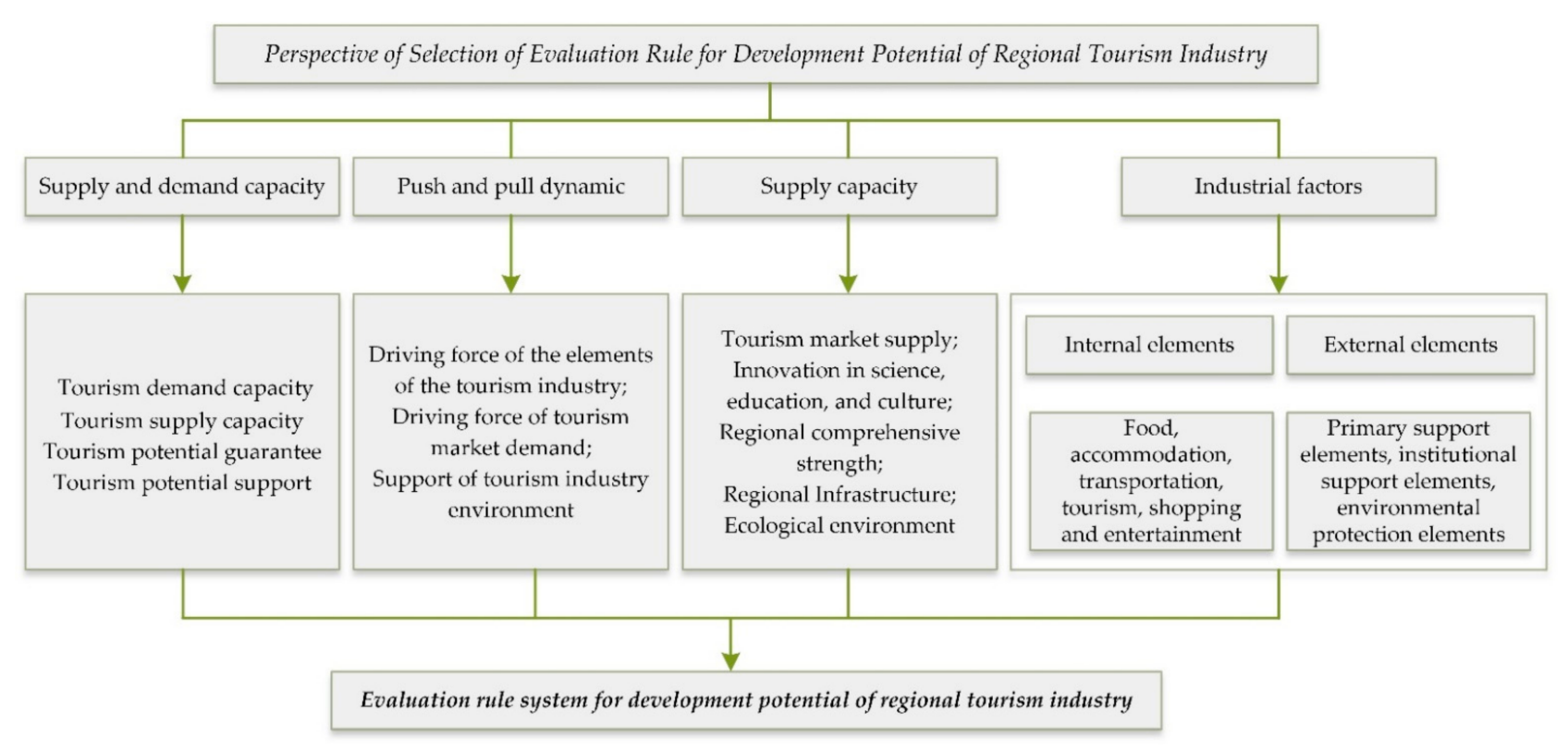

Figure 2. Evaluation rules for the development potential of regional tourism industry.

\subsection{Theoretical Framework of Evaluation Index System}

\subsubsection{Selection of Layer and Factor}

The Factor Layers of Destination's Supply and Consumption Capacity $\left(X_{1}\right)$

The potential regional model is based on the spatial interaction between the destination and the source place. Therefore, its influencing factors lie in the supply of the destination and the demand of the source place. In the context of the destination supply level, the index system directly affecting the supply and consumption potential of regional tourism mainly includes the number of tourism enterprises, total amount of fixed investment in tertiary industry, the number of tourism employees, the number of tourism training organizations, the annual tourism environment capacity, the number of kilometers of traffic operation, the number of $5 \mathrm{G}$ base stations [49-53]. On the other hand, the index systems indirectly affecting the supply and consumption potential of regional tourism mainly includes vegetation coverage, per capita park area, total utilization of foreign capital, the number of sanitation facilities, carbon emissions from the tourism industry and tourists, per capita public cultural facilities, and telecommunications business volume [54-56].

The Factor Layers of Source Place's Demand and Purchasing Power $\left(X_{2}\right)$

In assessing the capacity of tourism as a tool for destination development, it is vital to have a satisfactory scale of tourism demand and a certain degree of stable annual reception [56]. In this study, the evaluation of demand potential in the potential regional model takes the source place's demand and purchasing power as one of the rule layers and involves factor layers such as total population in source place, economic development level, travel rate, the purchasing power of tourism products, per capita disposable income, distance to destination and transportation cost, Engel coefficient, consumer confidence index, and expenditure on education, culture, and entertainment $[49,57]$.

The Factor Layers of the Development Value of Destination Resource $\left(X_{3}\right)$

Compared with the large-scale regional structure, the provincial tourism destination belongs to the mesoscale category, and its structure is manifested in the interaction of landscape combination, landscape unit, and regional landscape combination structure 
mechanism [58]. At the same time, access to practical information on climate resources has become a central element of tourism management as there is growing recognition that extreme weather events can have a devastating impact on tourism activities and facilities, which in turn affects the sustainable development of tourism [59]. Therefore, in tourism resources, its development value is mainly reflected in the abundance and density of landscape resources, cultural value, historical value, aesthetic value, artistic value, entertainment value, scientific value, and landscape's climate resources [60]. Among them, landscape resources involve nature reserve, cultural heritage sites, wet land landscape, and forest landscape; climate resources involve temperature, customs, humidity, and frost days.

\section{The Factor Layers of Destination's Tourism Industry Contribution Capacity $\left(X_{4}\right)$}

The contribution of tourism development to regional sustainable development is mainly reflected in economic contribution, employment contribution, and advanced tourism adaptability. The regional economic contribution of tourism development is reflected in share of tourism value-added to GDP, total tourism income, visa policy, and its utilization rate [61]. Employment contribution refers to the direct and indirect employment contribution of tourism. Finally, advanced tourism adaptability is the conscious and planned management of the existing resource, not accidental or unplanned management, affected by the environmental factors (business climate index) and business conditions (the revenue of food and beverages and accommodation, scenic spots, transportation, and shopping) [62]. Based on the statistical characteristics of China's social economy, this study uses factor layers such as business climate index and enterprise income to evaluate the advanced tourism adaptability of the target area.

\subsubsection{Evaluation Index System}

Based on the above rule layers and factor layers, the evaluation index system of TDP is composed of several rule layers, different sub-rule layers can reflect the rule layers, and a different factor layer reflects each sub-rule layer. In the context of the scientific, systematic, comparative, and hierarchical evaluation of TDP, this study selects the destination's supply and consumption capacity $\left(X_{1}\right)$, source place's demand and purchasing power $\left(X_{2}\right)$, the development value of destination resource $\left(X_{3}\right)$, destination's tourism industry contribution capacity $\left(X_{4}\right)$ as the four rule layers for evaluating provincial destination TDP $(Y)$. The rule layers consist of nine sub-rule layers and thirty-seven-factor layers (as shown in Table 1).

Table 1. The evaluation index system of TDP.

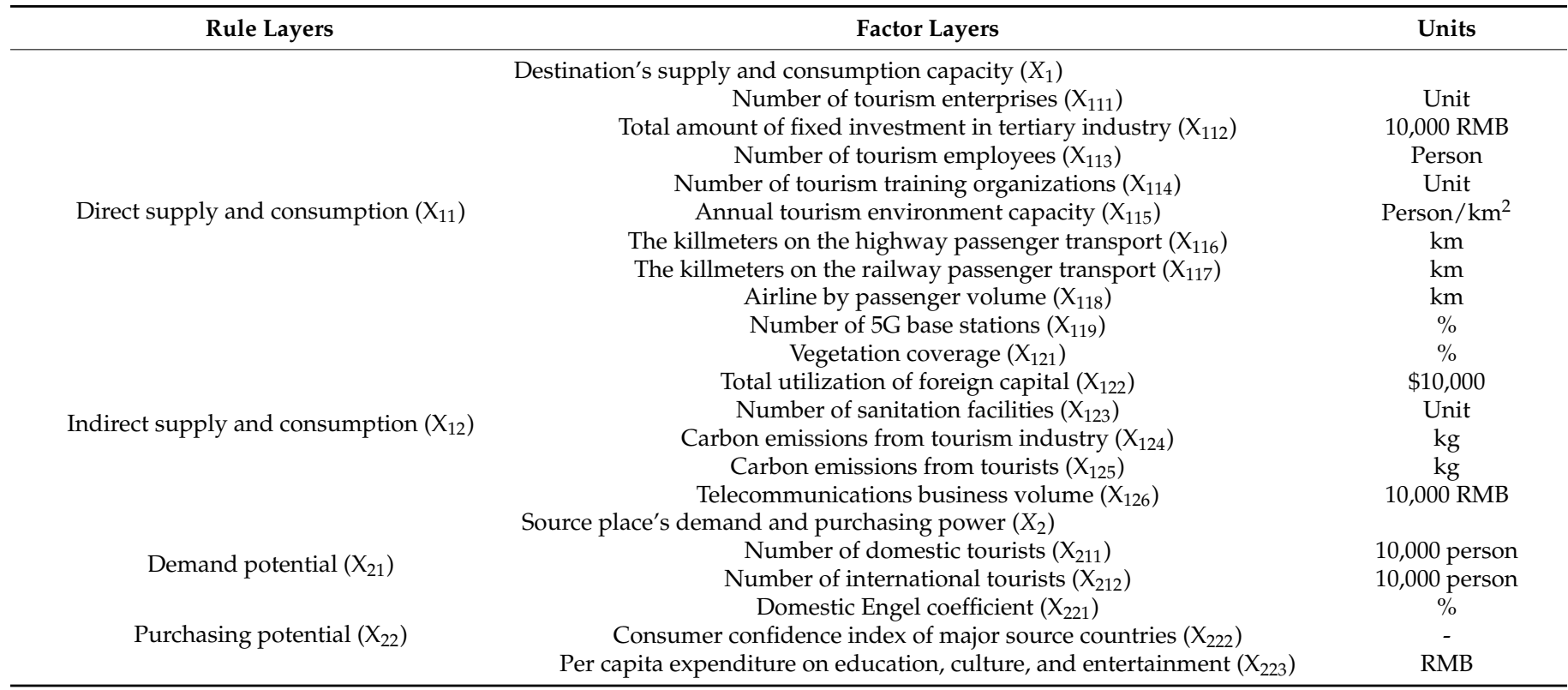


Table 1. Cont.

\begin{tabular}{|c|c|c|}
\hline Rule Layers & Factor Layers & Units \\
\hline \multirow{4}{*}{ Value of landscape resources $\left(X_{31}\right)$} & Development value of destination resource $\left(X_{3}\right)$ & \\
\hline & Nature reserve $\left(X_{311}\right)$ & Unit \\
\hline & Cultural heritage sites $\left(\mathrm{X}_{312}\right)$ & Unit \\
\hline & Wet land landscape $\left(X_{313}\right)$ & 10,000 hector \\
\hline \multirow{5}{*}{ Value of climate resources $\left(X_{32}\right)$} & Forest landscape $\left(\mathrm{X}_{314}\right)$ & 10,000 hector \\
\hline & Annual frost-free day $\left(X_{321}\right)$ & Day \\
\hline & Mean annual temperature $\left(X_{322}\right)$ & ${ }^{\circ} \mathrm{C}$ \\
\hline & Mean wind speed $\left(X_{323}\right)$ & $\mathrm{m} / \mathrm{s}$ \\
\hline & Mean annual humidity $\left(\mathrm{X}_{324}\right)$ & $\%$ \\
\hline \multirow{3}{*}{ Economic contribution $\left(\mathrm{X}_{41}\right)$} & Contribution of destination tourism industry $\left(X_{4}\right)$ & \\
\hline & Total tourism income $\left(\mathrm{X}_{411}\right)$ & $10,000 \mathrm{RMB}$ \\
\hline & The share of tourism value-added to GDP $\left(X_{412}\right)$ & $\%$ \\
\hline \multirow{2}{*}{ Employment contribution $\left(X_{42}\right)$} & Direct employment contribution of tourism $\left(\mathrm{X}_{421}\right)$ & $\%$ \\
\hline & Indirect employment contribution of tourism $\left(\mathrm{X}_{422}\right)$ & $\%$ \\
\hline \multirow{5}{*}{ Advanced tourism adaptability $\left(\mathrm{X}_{43}\right)$} & Business climate index $\left(\mathrm{X}_{431}\right)$ & _- \\
\hline & International revenue of scenic spots $\left(X_{432}\right)$ & $\$ 10,000$ \\
\hline & International revenue of food and beverages and accommodation $\left(\mathrm{X}_{433}\right)$ & $\$ 10,000$ \\
\hline & International revenue of tourism transportation $\left(X_{434}\right)$ & $\$ 10,000$ \\
\hline & International revenue of tourism shopping $\left(X_{435}\right)$ & $\$ 10,000$ \\
\hline
\end{tabular}

\section{Research Method}

\subsection{Research Area}

In view of the completeness of the administrative division of the provincial unit and the unity and similarity of the statistical caliber, this study selects the part of the city clusters that has the complete provincial administrative division, namely, Henan and Chongqing within the city clusters in central Henan province and around Chengdu and Chongqing, respectively. As the statistical calibers of Hong Kong, Macao, and Taiwan regions are not consistent with other provincial units, they are not included in the selection of the research area. Additionally, in the context of the national strategic decision of Hainan International Tourism Island, this study chose Hainan as the provincial unit. Therefore, the study selected 21 provincial units, combined with the ancient Silk Road and maritime trade routes, and divided the selected 21 provincial units into two regions, namely, the Belt with the northwest and inland regions as the main area, and the Road with the provinces in the northeast, coastal, and southwestern regions in China (as shown in Figure 3).

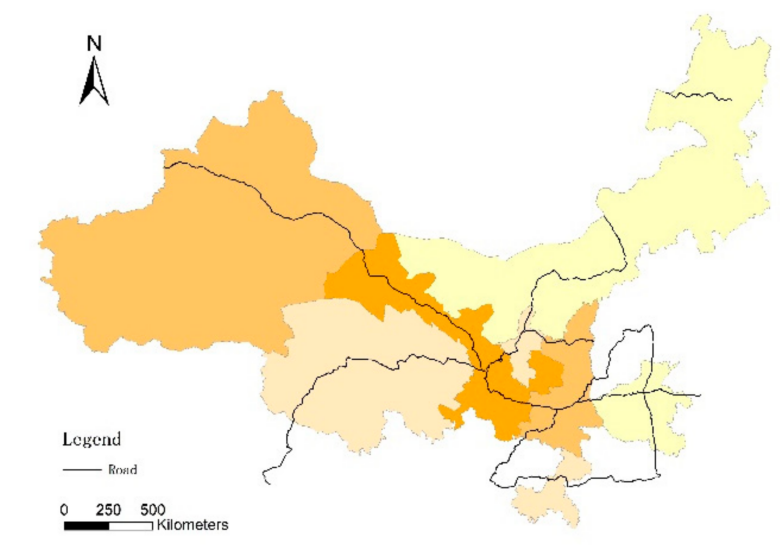

(a) Belt with Provincial Units along the Route of China

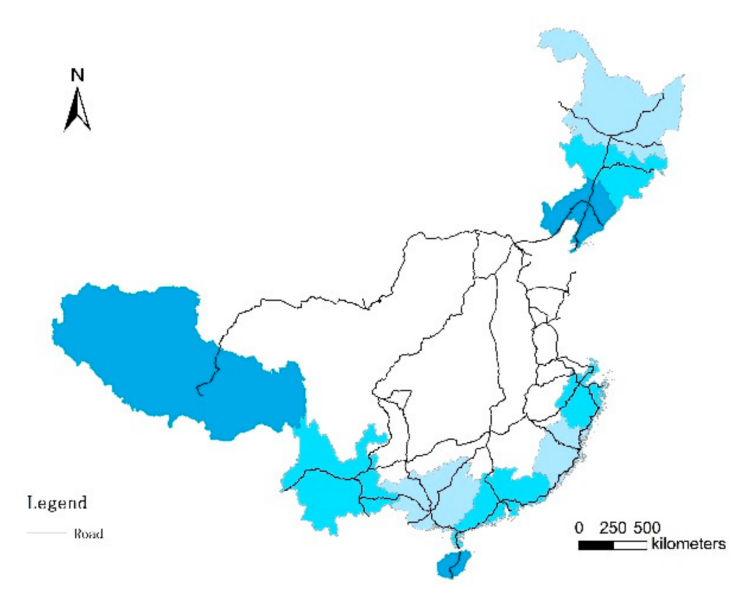

(b) Road with Provincial Units along the Route of China

Figure 3. Research area. 


\subsection{Data Resources}

The comprehensive evaluation of TDP needs to obtain data from the thirty-one-factor layers of the four rule layers, such as the destination's supply and consumption capacity, source place's demand, and purchasing power, the development value of destination resource, destination's tourism industry contribution capacity. The data mainly derive from the 2020 Statistical Yearbook and Statistical Bulletin of 21 provincial units along the Belt and Road in China. Furthermore, they also refer to the China Statistical Yearbook 2020, the China Cultural and Tourism Statistics Yearbook 2020, and the HBN Global Financial and Trade Statistics Database.

\subsection{The Estimation of Potential Index}

The standard methods used in the evaluation of TDP are SWOT, descriptive analysis, Item Response Theory, GIS, stakeholders' assessment. However, most of them being evaluated from the supply side, the dominant position of tourism supply evaluation may lead to one-sided results [63]. Some studies have included corresponding conceptual indicators in analytical models and frameworks of TDP to avoid these problems, but this makes it difficult for the studies to evaluate from a purely market-based perspective [64]. This study will use a multi-indicator comprehensive evaluation model to estimate the TDP in the provinces along the Belt and Road in China. The basic principle of the evaluation model is shown as formula: $Y=\omega_{1} X_{1}+\omega_{2} X_{2}+\cdots+\omega_{i} X_{i}$. Among the formula, $Y$ represents TDP, the larger the $Y$ value, the greater the development potential. $X_{i}$ means the overall score of the $i$ th TDP evaluation layer. The overall score of $X_{i}$ is obtained by summing the original assignments of the factor layers of TDP included in the $i$ th layer after standardization by the extreme difference method. $\omega_{i}$ means the weight of the $i$ th TDP evaluation layer.

In the multi-indicator comprehensive evaluation context, prior tourism studies often use the AHP method to determine each indicator's weight. Since the AHP method mainly derives from the score by experts, the determination of weight might be subjective. Furthermore, the correlation between indicators (factor layers in this study) can also cause overlap of indicator information, leading to deviations. However, studies have shown that principal component analysis (PCA) in factor analysis can overcome the shortcomings of subjective weight determination and ensure objectivity and rationality. Note that the primary purpose of the principal component analysis used in this study is to ascertain the weighting of each index to the rule layer, which is different from the purpose of exploratory factor analysis (EFA) in common sense.

When determining the weight of a factor layer by the principal component analysis, firstly, the weight of each factor layer in the different principal components is estimated by the extraction of the square root of the quotient of the factor loading and its corresponding eigenvalue. Then, weighted by the variance explained of the principal component, the initial value of the weight of indicator is obtained after a weighted average of the weight of each indicator in different principal components, as shown in the formula. Because the sum of all factor layer's weights is 1, the factor layer's weights need to be normalized based on the comprehensive model.

\section{Results}

\subsection{Index System and Model}

However, due to the complexity of statistical data collection and statistical caliber, some values in the ideal evaluation index system (Table 1) cannot be directly obtained. Therefore, based on the original structure, this study has eliminated and replaced some factor layers that meet the content and logical requirements of the original one. As shown in Table 2, the eliminated factor layer is $X_{412}$ (the share of tourism value-added to GDP) because its provincial data (not as the national data in prior studies) is difficult to collect and obtain. The replaced factor layers are as follows: $X_{124}$ (carbon emissions from tourism industry) and $X_{125}$ (carbon emissions from tourists) are replaced by new factor layer $X_{127}$ 
(environmental infrastructure investment). As carbon emission data are difficult to obtain, they are replaced with environmental protection-related factor layer from the perspective of environmental supply to emphasize the continuity of logic. Furthermore, $X_{211}$ (number of domestic tourists) and $X_{212}$ (number of domestic tourists) are replaced by $X_{213}$ (tourist reception). $X_{421}$ (direct employment contribution of tourism) and $X_{422}$ (indirect employment contribution of tourism) are replaced by $X_{423}$ (employment contribution of tourism).

Table 2. Multidimensional Scale for Evaluation of TDP of Provincial Destinations along the Belt and Road in China.

\begin{tabular}{|c|c|c|c|}
\hline Rule Layers & Sub-Rule Layers & Factor Layers & Weight (\%) \\
\hline \multirow{13}{*}{$\begin{array}{c}\text { Destination's supply and } \\
\text { consumption capacity }\left(X_{1}\right) \\
(25.73 \%)\end{array}$} & \multirow{9}{*}{$\begin{array}{l}\text { Direct supply and } \\
\text { consumption } \\
\left(X_{11}\right) \\
(64.61 \%)\end{array}$} & Number of tourism enterprises $\left(X_{111}\right)$ & 8.62 \\
\hline & & Total amount of fixed investment in tertiary industry $\left(X_{112}\right)$ & 9.45 \\
\hline & & Number of tourism employees $\left(X_{113}\right)$ & 8.04 \\
\hline & & Number of tourism training organizations $\left(X_{114}\right)$ & 3.50 \\
\hline & & Annual tourism environment capacity $\left(X_{115}\right)$ & 5.29 \\
\hline & & The kilometers on the highway passenger transport $\left(X_{116}\right)$ & 10.67 \\
\hline & & The kilometers on the railway passenger transport $\left(X_{117}\right)$ & 6.22 \\
\hline & & Airline by passenger volume $\left(X_{118}\right)$ & 6.63 \\
\hline & & Number of $5 \mathrm{G}$ base stations $\left(\mathrm{X}_{119}\right)$ & 6.19 \\
\hline & \multirow{4}{*}{$\begin{array}{l}\text { Indirect supply and } \\
\text { consumption }\left(X_{12}\right) \\
(35.39 \%)\end{array}$} & Total utilization of foreign capital $\left(\mathrm{X}_{122}\right)$ & 9.73 \\
\hline & & Number of sanitation facilities $\left(\mathrm{X}_{123}\right)$ & 9.01 \\
\hline & & Telecommunications business volume $\left(\mathrm{X}_{126}\right)$ & 10.97 \\
\hline & & Environmental infrastructure investment $\left(\mathrm{X}_{127}\right)$ & 5.67 \\
\hline \multirow{4}{*}{$\begin{array}{l}\text { Source place's demand and } \\
\text { purchasing power }\left(X_{2}\right) \\
(13.05 \%)\end{array}$} & $\begin{array}{l}\text { Demand potential }\left(X_{21}\right) \\
(28.59 \%)\end{array}$ & Tourist reception $\left(\mathrm{X}_{213}\right)$ & 28.59 \\
\hline & & Engel coefficient $\left(\mathrm{X}_{221}\right)$ & 24.04 \\
\hline & $\begin{array}{l}\text { Purchasing potential }\left(X_{22}\right) \\
\qquad(71.41 \%)\end{array}$ & Consumer confidence index of major source countries $\left(X_{222}\right)$ & 21.81 \\
\hline & & $\begin{array}{c}\text { Per capita expenditure on education, culture, and } \\
\text { entertainment }\left(\mathrm{X}_{223}\right)\end{array}$ & 25.55 \\
\hline \multirow{8}{*}{$\begin{array}{c}\text { Development value of } \\
\text { destination resource } \\
\qquad\left(X_{3}\right) \\
(31.77 \%)\end{array}$} & \multirow{4}{*}{$\begin{array}{l}\text { Value of landscape resources } \\
\qquad\left(X_{31}\right) \\
(46.13 \%)\end{array}$} & Nature reserve $\left(X_{311}\right)$ & 9.53 \\
\hline & & Cultural heritage sites $\left(\mathrm{X}_{312}\right)$ & 18.37 \\
\hline & & Wet land landscape $\left(X_{313}\right)$ & 1.76 \\
\hline & & Forest landscape $\left(\mathrm{X}_{314}\right)$ & 16.48 \\
\hline & \multirow{3}{*}{$\begin{array}{l}\text { Value of climate resources } \\
\qquad\left(X_{32}\right) \\
(53.87 \%)\end{array}$} & Annual frost-free day $\left(X_{321}\right)$ & 18.61 \\
\hline & & Mean annual temperature $\left(\mathrm{X}_{322}\right)$ & 21.09 \\
\hline & & Mean annual humidity $\left(X_{324}\right)$ & 14.18 \\
\hline & $\begin{array}{l}\text { Economic contribution }\left(X_{41}\right) \\
(12.56 \%)\end{array}$ & Total tourism income $\left(\mathrm{X}_{411}\right)$ & 12.56 \\
\hline \multirow{6}{*}{$\begin{array}{l}\text { Contribution of destination } \\
\text { tourism industry }\left(X_{4}\right) \\
(29.45 \%)\end{array}$} & $\begin{array}{c}\text { Employment contribution } \\
\left(X_{42}\right) \\
(10.31 \%)\end{array}$ & Employment contribution of tourism $\left(\mathrm{X}_{423}\right)$ & 10.31 \\
\hline & \multirow{5}{*}{$\begin{array}{l}\text { Advanced tourism } \\
\text { adaptability }\left(X_{43}\right) \\
(77.12 \%)\end{array}$} & Business climate index $\left(\mathrm{X}_{431}\right)$ & 12.26 \\
\hline & & International revenue of scenic spots $\left(\mathrm{X}_{432}\right)$ & 16.21 \\
\hline & & $\begin{array}{l}\text { International revenue of food and beverages and } \\
\text { accommodation }\left(X_{433}\right)\end{array}$ & 16.18 \\
\hline & & International revenue of tourism transportation $\left(X_{434}\right)$ & 16.19 \\
\hline & & International revenue of tourism shopping $\left(X_{435}\right)$ & 16.28 \\
\hline
\end{tabular}

As shown in Table 2, the assignments of each factor layer are operable and accessible. The factor layers selected can be quantified, and most of the original assignments can be obtained directly from the social, economic, cultural, scientific, technological, and environmental development figures released by provincial or national governments.

According to the data of 21 provinces along the Belt and Road in China in 2019, the factor layers in Table 1 are assigned and standardized. Through SPSS 24.0, the fourteenfactor layers of the rule layer $X_{1}$ (destination's supply and consumption capacity) were analyzed with factor analysis. However, $X_{121}$ (vegetation coverage) was eliminated because its commonality was less than 0.5 in the first factor analysis. In the second factor analysis, firstly, KMO and Bartlett's Test was conducted. The results showed that the KMO is 0.620, which is greater than the suggested threshold ( $>0.6)$. Furthermore, the $p$-value of Bartlett's Test is $0.000\left(\chi^{2}=265.152, d f=78\right)$, indicating that the selected data are suitable for factor analysis. Then, three components with eigenvalues greater than one were extracted. Among them, the variance explained of component 1 is $53.936 \%$, the variance explained of component two is $17.741 \%$, and the variance explained of component three is $9.258 \%$. 
The cumulative variance explained of the three components is $80.936 \%$, which is higher than $80 \%$, indicating that these three components could effectively explain most of the information of the original factor layers. Based on the number of factor loadings of each factor layer, the eigenvalue of the common factor and the variance explained, this study uses principal component analysis as an approach for determining the factor layer's weight to calculate the weight of each factor layer $\left(X_{111}-X_{127}\right)$ in the index system to the rule layer $\left(X_{1}\right)$, as shown in Table 3.

Table 3. The Loading and Weight of Each Factor Layer of the Rule Layer $X_{1}$.

\begin{tabular}{ccccccccc}
\hline \multirow{2}{*}{ Factor Layers } & \multicolumn{2}{c}{ Factor Loadings } & \multicolumn{2}{c}{ Factor Layers' Weights in Principal Components } & \multicolumn{2}{c}{ Overall Index Weight } \\
\cline { 2 - 8 } & $\mathbf{C 1}$ & $\mathbf{C 2}$ & $\mathbf{C}$ & $\mathbf{C 1}$ & $\mathbf{C 2}$ & $\mathbf{C 3}$ & Initial Value & Normalized Value \\
\hline$X_{127}$ & 0.952 & 0.129 & 0.116 & 0.360 & 0.085 & 0.106 & 0.270 & 0.110 \\
$X_{112}$ & 0.883 & 0.178 & 0.143 & 0.333 & 0.117 & -0.130 & 0.233 & 0.095 \\
$X_{113}$ & 0.865 & 0.089 & 0.064 & 0.327 & -0.059 & -0.058 & 0.198 & 0.080 \\
$X_{111}$ & 0.855 & 0.001 & 0.028 & 0.323 & 0.001 & -0.026 & 0.212 & 0.086 \\
$X_{123}$ & 0.851 & 0.032 & 0.121 & 0.321 & -0.021 & 0.110 & 0.222 & 0.090 \\
$X_{119}$ & 0.847 & 0.362 & 0.081 & 0.320 & -0.238 & -0.074 & 0.152 & 0.062 \\
$X_{122}$ & 0.800 & 0.062 & 0.455 & 0.302 & -0.041 & 0.415 & 0.240 & 0.097 \\
$X_{126}$ & 0.767 & 0.196 & 0.239 & 0.290 & -0.129 & -0.218 & 0.140 & 0.057 \\
$X_{118}$ & 0.702 & 0.392 & 0.415 & 0.265 & -0.258 & 0.378 & 0.163 & 0.066 \\
$X_{117}$ & 0.127 & 0.891 & 0.070 & 0.048 & 0.587 & -0.064 & 0.153 & 0.062 \\
$X_{115}$ & 0.092 & 0.750 & 0.435 & -0.035 & 0.494 & 0.396 & 0.130 & 0.053 \\
$X_{116}$ & 0.625 & 0.722 & 0.014 & 0.236 & 0.475 & 0.013 & 0.263 & 0.107 \\
$X_{114}$ & 0.519 & 0.210 & 0.716 & 0.196 & 0.138 & -0.653 & 0.086 & 0.035 \\
\hline
\end{tabular}

Note: $\mathrm{C}=$ Component. The Eigenvalue of each principal component $\left(\lambda_{i}\right)$ is as follows: $\lambda_{1}=7.012 ; \lambda_{2}=2.306 ; \lambda_{3}=1.204$. The extraction of Eigenvalue of each principal component $\left(\sqrt{\lambda_{j}}\right)$ is as follows: $\sqrt{\lambda_{1}}=2.648 ; \sqrt{\lambda_{2}}=1.519 ; \sqrt{\lambda_{3}}=1.097$. The variance explained of each principal component $\left(C_{J}\right)$ is as follows: $C_{1}=53.936 ; C_{2}=17.741 ; C_{3}=9.258$.

Under the same logic, the weights of other factor layers to the corresponding rule layers and their overall score can be determined. Note that $X_{323}$ (mean wind speed) was eliminated because its factor loading was lower than 0.5 . Therefore, the final evaluation index system of TDP is composed of thirty-one-factor layers. The weights of each rule layer, sub-rule layer, and factor layer are gained (as shown in Table 2).

Based on the results in Table 2, the weight of the sub-rule layer to the corresponding rule layer is determined through principal component analysis to calculate the score of each rule layer. Then, after the score is normalized, SPSS 24.0 is used to perform principal component analysis again to determine the weights of each rule layer $\left(X_{2}, X_{3}, X_{4}\right)$ to TDP $(Y)$ [1]. Finally, the measurement model of TDP index of China's provincial destination along the Belt and Road could be determined in the formula: $Y=0.2573 X_{1}+0.1305 X_{2}+$ $0.3177 X_{3}+0.2945 X_{4}$. The final evaluation index system of TDP is shown in Table 2 .

\subsection{The Results of Rule Layers}

TDP index of China's 21 provincial units along the Belt and Road in 2019 is showed in Table 4.

The results show that there are significant differences in the TDP scores of each provincial unit. In the context of the evaluation layers of TDP, Guangdong has the greatest potential (0.7840), which is higher than the global mean of 0.4427 and 1.57 times as much as Zhejiang (the 2nd). Qinghai Province has the lowest potential, with a total score of 0.1179, which is lower than the global mean of 0.1934. Among the Belt provincial units, Henan has the greatest potential, with a total score of 0.4183 , which is higher than the global mean of 0.1070 . Qinghai has the lowest potential, 0.3004 behind Henan. Among the Road provincial units, Guangdong has the greatest potential. Tibet has the lowest potential, which is lower than the global mean of $0.1611,0.6038$ behind Guangdong. 
Table 4. TDP score of provincial units along the Belt and Road in China.

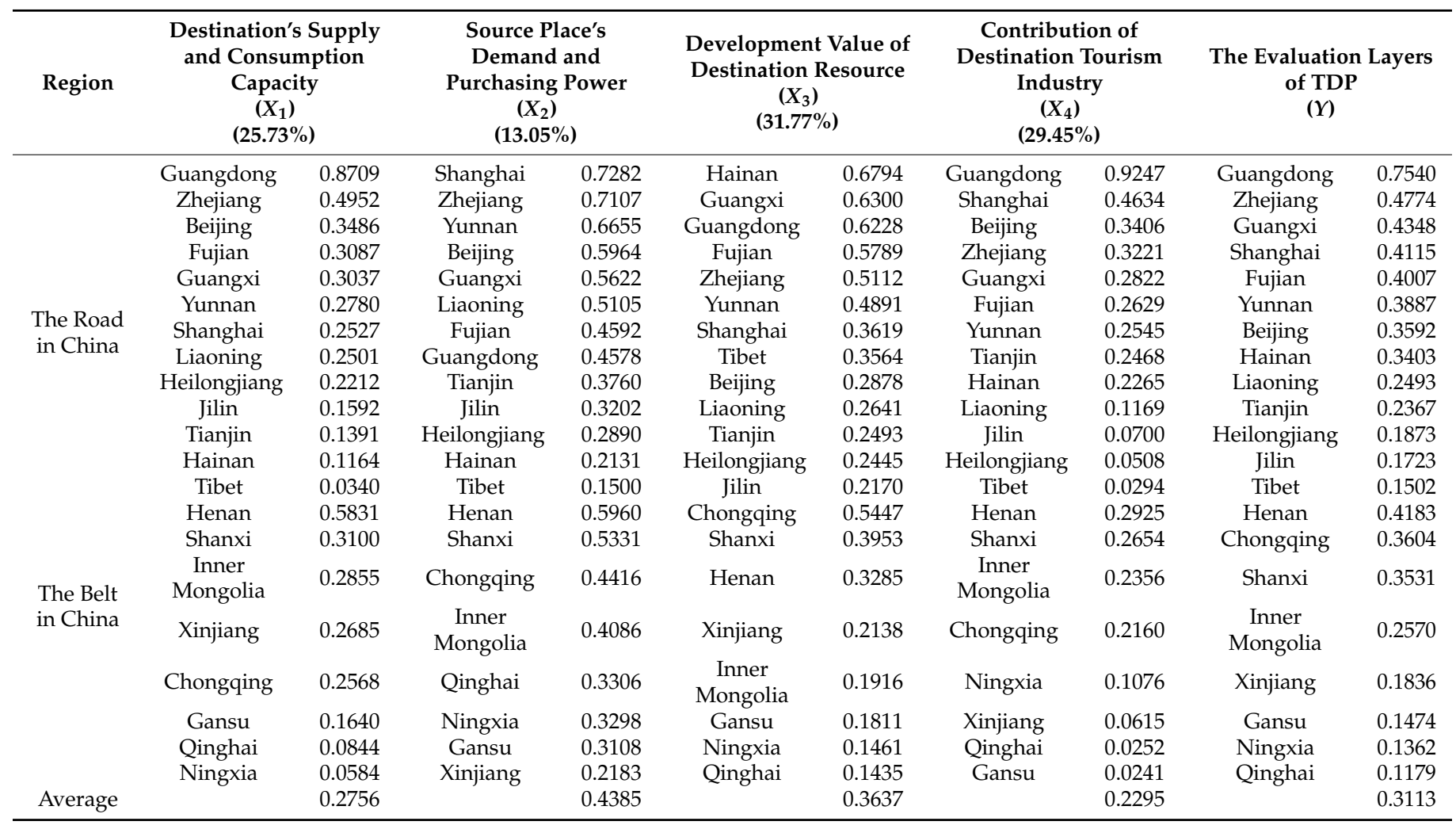

In the context of four rule layers, the total score difference of each provincial unit is significant. Guangdong has the greatest destination's supply and consumption capacity in the first rule layer, which is 0.5953 higher than the global mean and 1.49 times as much as Henan. The lowest destination's supply and consumption capacity is Tibet, which is lower than the global mean value of 0.2416. Among the provincial units of the Belt, Henan has the greatest destination's supply and consumption capacity, with a total score of 0.5831 , which is higher than the global mean of 0.3075; Ningxia has the lowest destination's supply and consumption capacity, 0.5247 behind Henan. Among the provincial units of the Road, Guangdong has the greatest destination's supply and consumption capacity, 25.61 times as much as Tibet.

In the second rule layer, Shanghai has the greatest source place's demand and purchasing power, with a total score of 0.7282 , followed by Zhejiang (0.7107), Yunnan (0.6655), Beijing (0.5964), and Henan (0.5960). Tibet has the lowest source place's demand and purchasing power, with a total score of 0.1500 . This potential order is consistent with the views in the "2016 China Online Travel Platform White Paper" by iResearch [65]. Among the Belt provincial units, Henan has the greatest source place's demand and purchasing power, with a total score of 0.5960 , which is higher than the global mean of 0.1575 . Xinjiang has the lowest source place's demand and purchasing power, which is only $36.63 \%$ of Henan. Among the Road provincial units, Shanghai has the greatest source place's demand and purchasing power, which is 4.85 times as much as Tibet.

In the third rule layer, Hainan has the greatest development value of destination resource, with a total score of 0.6794 , and Qinghai has the lowest development value of destination resource, with a total score of 0.1435 . Among the Belt provincial units, Chongqing has the greatest development value of destination resource, with a total score of 0.5447, which is higher than the global mean of 0.181. Qinghai has the lowest development value of destination resource, which is only $26.34 \%$ of Chongqing. Among the Road provincial units, Hainan has the greatest development value of destination resource, and 
Jilin has the lowest development value of destination resource, which is only $31.94 \%$ of Hainan.

In the fourth rule layer, Guangdong has the greatest contribution to the destination tourism industry, with a total score of 0.9247 , twice that of Shanghai, and 38.37 times as much as Gansu. Among the Belt provincial units, Henan has the greatest development value of destination resource, with a total score of 0.2925 , which is higher than the global mean of 0.063 . Gansu has the lowest development value of destination resource, 0.1490 behind Henan. Among the Road provincial units, Guangdong contributes the most to the development value of destination resources, which is 31.45 times as much as Tibet.

\subsection{Spatial Characteristics}

Furthermore, all the potential indexes are multiplied in Table 4 by 100 and abstracted in the provinces along the Belt and Road in China. The measured total scores of each provincial unit's TDP are used as the calculation condition [66]. Then, this study uses ArcGIS 10.2 to estimate the kernel density analysis and simulates the spatial distribution characteristics of the TDP of the areas along with the Belt and Road areas in China. The results are shown in Figure 4.

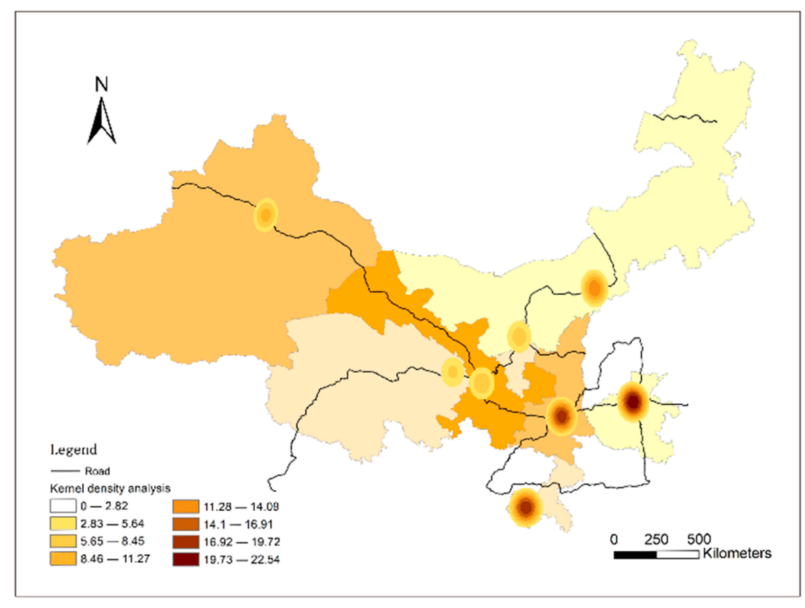

(a) The Kernel Density of the Provincial TDP Index along the Belt in China

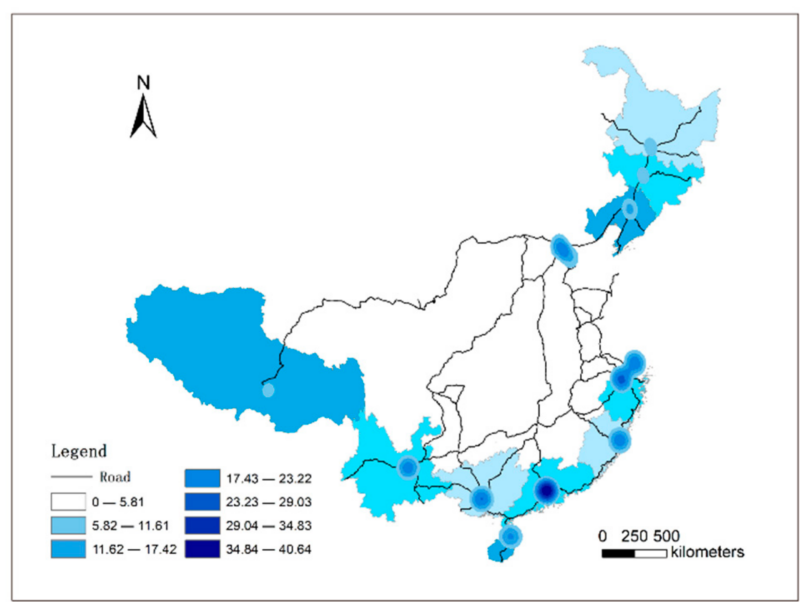

(b) The Kernel Density of the Provincial TDP Index along the Road in China

Figure 4. The kernel density of the provincial TDP index along the Belt and Road in China.

Figure 4a shows that the TDP of Shaanxi, Chongqing, and Henan has reached high peaks, and the potential agglomeration phenomenon is significant, which is the region with the highest level of TDP. The peak TDP of Inner Mongolia and Xinjiang is second only to the Chongqing-Shaanxi-Henan line, the secondary center. Although Gansu, Ningxia, Qinghai, and other regions also have large-scale high-TDP agglomeration phenomena, compared with the central line area, these provinces have lower TDP scores and weak agglomeration phenomena. However, there is still a tendency for these regions to develop toward the peak of potential. Based on the above results, the TDP center in the areas along the Belt in China is the Henan-Shaanxi-Chongqing line. The periphery areas around the center, such as Inner Mongolia, Xinjiang, Gansu, Ningxia, and Qinghai, are the sub-centers.

Figure $4 \mathrm{~b}$ shows that the TDP of Guangdong has reached the highest score, the potential agglomeration phenomenon is common, and the spatial distribution is relatively homogeneous. Therefore, Guangdong has the highest potential level among all the provincial units. As sub-centers, the potential peaks of Zhejiang and Beijing-Tianjin regions are second only to Guangdong Province, and TDP agglomeration is significant and extensive in scale, with a relatively wide range. Furthermore, their potential peaks exist a significant trend toward Guangdong. Shanghai, Fujian, Yunnan, Guangxi, Hainan, Liaoning, 
Heilongjiang, Jilin, and other provinces are second only to sub-centers in TDP and agglomeration scale. Although they are central fringe areas, they also have a significant trend toward the TDP centers of Guangdong. Besides, Heilongjiang, Jilin, and Tibet have the lowest TDP and the weakest agglomeration phenomenon. Based on the above results, the TDP center in the areas along the Road in China in Guangdong, the sub-centers are Zhejiang and Beijing-Tianjin areas. Shanghai, Fujian, Yunnan, Guangxi, Hainan, Liaoning, and other provincial units are the periphery areas around the center. Heilongjiang, Jilin, and Tibet are entirely peripheral areas with TDP.

\section{Discussions and Conclusions}

\subsection{Discussions}

The resource development structure of mesoscale tourism destinations is manifested in the relationship between landscape combination, landscape unit, and regional landscape combination mechanism. Good climate resources and extreme climate events are the facilitators of this mechanism. Therefore, this study pays attention to landscape resources and climate resources when discussing the development value of destination resources of TDP. However, prior studies on the evaluation of TDP pay more attention to tourism resources or tourist attractions when analyzing destination resources. Interestingly, the results showed that the development value of destination resources has the highest contribution to its TDP and is the sub-rule with the highest weight score. This finding is consistent with the conclusions of prior studies on TDP that the development value of destination resource is one of the essential sub-rule layers in evaluating TDP [5,47,63]. For example, when evaluating the TDP of rural heritage sites, Yan, Gao, and Zhang [63] found that the weight score of rural aesthetic value and cultural resources is 0.349 , and the weight score of the rule layer of development value of destination resources in this study is 0.318 . These two results are very close. Furthermore, when using the entropy method to evaluate the TDP of countries along the Belt and Road in terms of economy, society, tourism resources, and environmental development potential, Wang and Zhang [5] argued that the main focus should be on improving the potential of tourism resources.

Additionally, by measuring the TDP index along the Belt and Road in China, it is found that there is an imbalance in the regional distribution of the TDP of mesoscale destinations in a large area. Furthermore, areas with high levels of socio-economic development have relatively large potential. The result is consistent with that of Puška et al. [67] that the government of Bosnia and Herzegovina needs to improve social and economic development in the region to stimulate the TDP of 6 villages in the Brčko District [67].

\subsection{Conclusions}

The evaluation of TDP is an essential basis for tourism destination management and decision-making, which can help local governments rationally allocate tourism resources and land use. In the countries along the Belt and Road, although China's tourism economy develops rapidly and has excellent potential for tourism competition, there are still significant regional differences and heterogeneous development of the provinces along the route. Therefore, it is of great significance to accurately evaluate the TDP of the provinces along the Belt and Road in China to promote the development of competition and cooperation in these regions. Based on the in-depth review of relevant literature, this study proposed a comprehensive evaluation index, established a regional TDP index model through the index assignment of the research area, and obtained the TDP index of the provinces along the Belt and Road in China. The specific conclusions are concluded as follows.

First, this study proposes a comprehensive index system that can effectively evaluate the TDP of mesoscale destinations. Based on comprehensively analyzing the prior studies of TDP, it is found that the TDP of mesoscale destination can be systematically and comprehensively showed by four rule layers, namely, the destination's supply and consumption capacity, the source place's demand, and purchasing power, the development value of the destination resource, the destination's tourism industry contribution capacity. The rule 
layers can be further subdivided into nine sub-rule layers; and the sub-rule layers consist of factor layers that can be directly quantified. Finally, a comprehensive index system suitable for the evaluation of the TDP of mesoscale destinations has a total of four rule layers, nine sub-rule layers, and thirty-seven factor layers. Each factor layer is assigned according to the official statistics of research areas along with the Belt and Road in 2019; and the weights of each rule layer, sub-rule layer, and factor layer are measured. The weights of each level of the TDP index system of the study area indicated that the contribution of the factors between the source place's purchasing potential and advanced tourism adaptability remains equilibrated. In contrast, there are significant differences in the contribution between the destination's supply and consumption capacity and development value of destination resource, which may be due to the complexity and diversity of factors impacting tourism sustainable development.

Furthermore, this study develops the evaluation model of the destination's TDP index of the provincial region in China along the Belt and Road through principal component analysis, which is $Y=0.2573 X_{1}+0.1305 X_{2}+0.3177 X_{3}+0.2945 X_{4}$. The higher value of the index is, the better the TDP is, and the stronger the tourism sustainable development ability is. On the contrary, the smaller the index, the weaker the TDP. Therefore, the weights of different rule layers in the TDP index show that the development value of destination resources of the provinces in China along the Belt and Road has the most significant impact on the TDP. This result indicates that provinces with a high value of landscape resources and ideal climatic conditions may have greater TDP. According to the order of the weights of each rule layer, followed by the contribution of the destination tourism industry and the source place's demand, the purchasing power owns the least impact. The model developed by this study provides a measurement tool for evaluating the TDP index of the provinces along the Belt and Road in China. The research approach of this model applies to the development of an index model of regional TDP in a general sense.

The results showed the TDP of the provincial region along the Road in China is higher than that of the Belt in 2019. The result is closely related to the fact that the development level of the tourism economy in the eastern coastal areas of China is much higher than that in the northwest and inland areas. Because the eastern coastal areas of China have strong tourism economic supply capacity, the scale of tourist demand and purchasing power is far greater than those in the northwest and inland areas. Among the provinces along the Road, the TDP of Guangdong is the greatest, and its vast potential is higher than that of other provincial regions. The possible explanation is that the development level of the tourism economy of Guangdong has been ranked first in the country since China's reform and opening up. Specifically, implementing "The Development Plan Outline of Guangdong-Hong Kong-Macao Bay Area" will greatly strengthen the TDP of Guangdong. Above all, this study argues that the TDP ranking of each provincial unit is consistent with its comprehensive strength of abundance of tourism resources and national economic and social development. For example, the TDP of Henan ranks fourth. The possible reasons are: Firstly, Henan is recognized as the core area for the inheritance and innovation of Chinese civilization. It carries China's five thousand years of history and has vibrant historical and cultural tourism resources. Secondly, the region is rich in high-grade natural tourism resources with well-known mountains in China, such as Mount Song, T'ai-hang Mountains, Funiu Mountain, etc. Thirdly, Henan's social and economic development strength usually ranks fifth in China.

The results indicated that there are significant differences in the spatial distribution of TDP in the research area. The estimation of kernel density indicated that the TDP factors in the eastern coastal area have a higher degree of concentration, followed by the central region, and the western region is relatively scattered. Furthermore, the TDP in the provincial region in China along the Belt has a distinct spatial distribution and a hierarchical agglomeration of TDP factors. Among them, Guangdong is the potential center with the greatest potential and the most significant agglomeration. The potential sub-centers are Zhejiang, the Beijing-Tianjin area, and the Chongqing-Shanxi-Henan line. 
The agglomeration of TDP factors is relatively significant. This spatial distribution feature is relatively consistent with the spatial distribution of China's tourism resources and socioeconomic factors. Shanghai, Fujian, Yunnan, Guangxi, Hainan, Liaoning, Inner Mongolia are at the edge of the potential center. The degree of spatial agglomeration of TDP factors in each provincial unit is relatively small. For example, although Shanghai has a high level of tourism economic development, the distribution of TDP factors in each urban area is reasonably balanced, and the agglomeration is not significant. Another example is that Yunnan attaches great importance to tourism development, implements the concept of All-in-one tourism in all regions of the province, and cultivates many central tourism cities, making TDP factors cover the region. However, it also has a relatively balanced spatial distribution with an insignificant agglomeration. Heilongjiang, Jilin, Tibet, Gansu, Ningxia, and Qinghai are in the periphery areas of the TDP.

\subsubsection{Theoretical Implications}

Prior studies of TDP mainly discussed the univariate potential model or multiindicator evaluation approach, which still has limitations for mesoscale tourism destinations. Given this, this study builds a comprehensive evaluation index system and corresponding index model from four rules and multiple sub-rules of resources, supply, demand, and economic contribution. This TDP model is suitable for evaluating and measuring the development potential of provincial destinations along the Belt and Road in China and provides a theoretical basis for the construction and evaluation of TDP models for other countries and their mesoscale destinations.

The TDP model proposed by this study includes four rule layers: the destination's supply and consumption capacity, the source place's demand and purchasing power, the development value of the destination resource, and the contribution of the destination tourism industry. Their potential indexes have theoretical guiding significance for the corresponding fields of regional tourism development. For example, the destination's supply and consumption capacity index can guide tourists to choose the most interesting destination. The source place's demand and purchasing power index can provide a theoretical basis for tourist destinations' market positioning and marketing decisions. The development value of the destination resource index can help tourism managers and operators make reasonable tourism investment decisions. The contribution of the destination tourism industry index can effectively guide the government to adjust the destination industry structure, improve the economic development level of the destination, increase the alternative source of income for the residents of the destination community, and ensure the sustainable development of rural areas.

In general, the TDP index model and spatial characteristics of the 'rule layer, sub-rule layer, factor layer' structure developed by this study have filled up the deficiencies of existing studies to a certain extent. This model extends the research field of TDP and has a specific reference value for the sustainable development of tourism destinations and the spatial allocation of land resources. Furthermore, the indexes of different layers can alleviate regional tourism development monopoly issues and two-level differentiation caused by regional differences in resource endowments, business philosophy, investment and financing capabilities, and policy systems. These indexes also provide future development decisions and inter-regional tourism competition and cooperation development for provincial units along the Belt and Road in China. The spatial visualization results of the regional TDP index presented by the study are helpful for regional governments to understand the importance of TDP within land use, grasp the scale and direction of the spatial allocation of tourism land, and achieve the improvement of destination land-use efficiency. Finally, the kernel density value reflects the spatial aggregation form of the layers of TDP. It provides a powerful resource for tourism decision-makers to make the spatial allocation of resources for future tourism development. Notably, it offers powerful theoretical guidance in the intensive use of land resources and the efficient development of tourism land formation. 


\subsubsection{Managerial Implications}

The evaluation of TDP can reflect its sustainable ability and the prospect of tourism development to provide a theoretical basis for correctly understanding and clarifying the cognition of tourism development. It also indirectly reflects the ability of sustainable tourism development. According to the total scores and TDP of the four rule layers in Table 4, guided by the strategy of the Belt and Road, this study proposed the approaches to enhance the sustainable development of tourism capacity and the provincial TDP.

Firstly, the results showed significant differences in the ability of tourism supply and tourism consumption among the provincial regions in China along the Belt and Road. The possible explanation can be attributed to the policy principle of tourism development in each province and the socio-economic development base of each province. Therefore, this study argued that the provincial region in China along the Belt and Road should carry out the idea of All-for-One Tourism ${ }^{1}$ in the whole area according to the actual situation. The principle of All-for-One Tourism can encourage the participation of the entire stakeholders, make full use of regional tourism economic management resources, and encourage all tourism-related enterprises and departments to participate in tourism development [68-70]. Note that destinations' residents should be fully motivated and utilize idle housing to develop the households that could benefit from the facilities and services of self-sustaining tourist accommodation (e.g., Airbnb).

Furthermore, residents and businesses should be encouraged to build eco-homes [71]. In 2018, Guangdong formulated an implementation plan to promote the development of All-for-One Tourism and achieved specific positive results. The most robust tourism supply and consumption capacity of Guangdong in this study prove the value of All-for-One Tourism. Therefore, for regions such as Hainan, Qinghai, Ningxia, and Tibet, where tourism supply and consumption capacity is much weaker, it is more important to promote the idea of All-for-One Tourism in all aspects. For example, these provinces could try to build eco-houses in areas with relatively fragile environments.

Secondly, China's online tourism has developed rapidly in recent years, and its comprehensive strength has exceeded offline tourism. The popularity of online payment and self-media information consultation, such as WeChat payment, Alipay, Weibo, and Tik-Tok, has stimulated the tourism consumption demand of about one billion Chinese residents. Therefore, this study suggested that the provincial units along the Belt and Road in China should promote the integration of the internet industry and tourism industry. The potential tourism demand can be fully exploited by online tourism websites, APP of tourism enterprises, and big data [55], which could enhance the scale of the target tourist market and help destination marketing organizers (DMOs) manage better growth of tourists' arrivals. Online tourism platforms cover the whole tourism industry chain and promote the deep integration of the internet and tourism. Among the study region, Shanghai is the top provincial unit in terms of size, number, and the output value of online tourism platforms. In the context of this, the development of online tourism platforms can enhance the ability of internet technology to tap the potential of tourism demand.

Thirdly, the development value of destination resources in each provincial unit is a kind of natural endowment ability. Therefore, firstly, it is necessary to rely on the dynamism of tourism enterprises to enhance the value of the tourism landscape through creative tourism planning. Second, adhere to the idea of harmony between man and nature, make full use of climatic conditions, and develop tourism products suitable for different seasons. Finally, tourism enterprises must promote technological innovation and improve tourism science and technology and the quality of human resources. Thus, the regional resources can be comprehensively developed and utilized. For example, Hainan Island has significant advantages in tourism landscape value and climatic conditions compared to other provinces. It is closely related to the relatively developed local highlevel hospitalities, online tourism enterprises, and shopping enterprises. Additionally, Guangdong, Fujian, Zhejiang, Chongqing, and other provincial areas have a relatively high potential for resource development, mainly due to their corporate innovation capacity. 
Therefore, strengthening the innovation capacity of tourism enterprises can effectively enhance their resource development potential.

Fourthly, in the new century, the tourism multiplier effect continues to be significant, especially in the aspects of transformation and upgrading of regional structure of tourism industry, the ability of the regional tourism to earn foreign exchange, and the contribution level of social employment. One of the important reasons is that the regional government attaches great importance to the impact of the tourism economy. Since the reform and opening up, attention has been paid to the development of the tourism industry in China. In the 1980s, the tourism industry got on the track of social and economic development and announced a series of development policies of tourism economic. For instance, the Opinions on Accelerating the Development of Tourism Industry issued by the State Council in 2009 had paid much attention to the tourism industry. However, there is still a lack of relevant policies on the sustainable development of the regional tourism industry. Therefore, this study recommends that the provincial tourism destinations along the Belt and Road China prioritize optimizing and improving economic policies and regulations for travel agencies, scenic spots, restaurants, accommodation, travel shops, market information companies, and other tourism industries. Based on this, the current study recommends that the tourism industry upgrade and improve tourism production efficiency. Alternatively, the relevant industries can learn from the British Model to prepare and operate various tourism associations to coordinate the competition among enterprises to enhance the contribution capacity of the tourism industry and realize the sustainable development of the provincial tourism economy.

Fifthly, enterprises are the most active factors in the development of tourism destinations, and their business climate index, human resource quality, and comprehensive profitability determine the advanced regional tourism adaptability to a great extent. Deepening international tourism cooperation among tourism enterprises can enhance entrepreneurs awareness of the significance of TDP and their ability of decision-making capacity and the promotion of tourism facilities and operational level. Given the importance of the entrepreneur's sense of location, the government should invest and organize more tourism activities to encourage enterprises to participate and communicate with others. Furthermore, it is also a fundamental approach for tourism developers to strengthen advanced tourism adaptability through increasing tourism benefits and reducing tourism costs. In addition, the government should implement tax reduction and create a fair development environment for tourism enterprises to adapt to the changing conditions and environment of tourism development in the destination [28], which can enhance the regional TDP.

Finally, due to the differences in the kernel density values of TDP of each provincial unit, the potential layers have different degrees of spatial aggregation. Therefore, provinces with different kernel density values need to adopt different spatial layout strategies. For provinces with relatively dense potential layers like Guangdong, Henan, Chongqing, Shanghai, and Shaanxi, tourism enterprises should concentrate their layout and use land resources efficiently to allocate TDP layers; and for the provincial units with smaller TDP kernel density values, such as Gansu, Inner Mongolia, Tibet, Heilongjiang, and Jilin, the efficiency of tourism land use should be improved.

\subsection{Limitations}

There are still some limitations in this study: first, this study only assigned values to evaluation indicators based on available statistics and selected most of the provincial units along the Belt and Road in China as the study area. Therefore, the evaluation and discussion of the TDP of other provincial units and other countries along the Belt and Road (including their provincial areas), where data are difficult to obtain, are insufficient. Thus, it is suggested to further verify the generalizability of the evaluation index system in these countries and regions in the future. Second, this study used principal component analysis to assign weights to the evaluation layers. Since the mainstream weighting methods include entropy and expert consultation methods [5], studies could use multiple weighting 
methods to measure the weights of the TDP evaluation system in the future to obtain more convincing weights and more accurate potential indexes.

Author Contributions: Conceptualization, Y.C., N.C. and Q.Y.; methodology, Y.L. and X.G.; software, Y.L. and X.G.; validation, Y.L., X.G. and M.Y.; formal analysis, Y.C., Y.L., X.G., N.C. and Q.Y.; investigation, Y.C. and Y.L.; resources, Y.C., Y.L. and M.Y.; data curation, Y.C., Y.L. and Q.Y.; writingoriginal draft preparation, Y.C., Y.L. and X.G.; writing-Q.Y. and N.C.; visualization, X.G.; supervision, Y.C., N.C. and Q.Y.; project administration, N.C. and Q.Y.; funding acquisition, N.C. and Q.Y. All authors have read and agreed to the published version of the manuscript.

Funding: This research was funded by the Major Project of China National Social Science Fund in Art, grant number 21ZD03; China National Social Science Fund, grant number 19BGJ007; Project for Science \& Technology Innovation Talents in Universities of Henan Province (Humanities and Social Sciences), grant number 2020-cx-002; Project for Young Backbone Teachers in Institutions of Higher Learning of Henan Province, grant number 2018GGJS023; Project for Postdoctoral Research of Henan University, grant number FJ3050A0670270; Research Project for Henan Provincial Social Science Federation, grant number SKL-2021-879.

Institutional Review Board Statement: Not applicable.

Informed Consent Statement: Not applicable.

Data Availability Statement: Data sharing not applicable.

Acknowledgments: The authors are particularly grateful to the editors and reviewers for their suggestions and comments on improving this study. The authors also thank Jianmei Zhou and He Ren, master of the School of Cultural Industry \& Tourism Management of Henan University, for their help in conclusions.

Conflicts of Interest: The authors declare no conflict of interest.

\section{Note}

1 The phrase 'All-for-One Tourism' was first mentioned in the Government Work Report in 2017. It refers to a new concept and mode of joint regional development. Tourism drives and promotes coordinated economic and social development through all-around systematic optimization and enhancement of regional economic and social resources. It benefits tourism resources, related industries, ecological environment, public services, institutional mechanisms, policies and regulations, and the quality of civilization to achieve organic integration of regional resources, integrated development of industries, and shared social construction.

\section{References}

1. Ministry of Commerce of the People's Republic of China. Vision and actions on jointly building Silk Road Economic Belt and 21st-Century Maritime Silk Road. Available online: http://zhs.mofcom.gov.cn/article/xxfb/201503/20150300926644.shtml (accessed on 15 February 2021).

2. Hao, Y.W.; Zhang, H. The realistic basis and path selection of international tourism cooperation of the cities along the Belt and Road. Qinghai Soc. Sci. 2019, 2, 58-65.

3. Wang, J.J. Research on new land-sea corridor linking up Belt and Road and the domestic and international dual circulation from the perspective of industrial chain. China Bus. Mark. 2020, 10, 3-16.

4. Wang, X.Y.; Han, X.X. The measurement of tourism efficiencies and spatial features of coastal port cities in China in the Belt and Road Initiative. J. Ocean. Univ. China 2018, 5, 36-42.

5. Wang, J.Y.; Zhang, H. Tourism competitive potential and tourism competitiveness in the countries along the Belt and Road. Qinghai Soc. Sci. 2019, 6, 62-68.

6. Zhou, Q.L.; Zhan, B.M. A study of service trade cooperation potential between China and the countries of Belt and Road -Based on the interna-tional competitiveness of service industry. West Forum 2017, 9, 111-124.

7. Liu, G.B. Research on the advancing path and policy innovation of the Belt and Road Initiative. Northeast Asia Forum $2019,4,128$.

8. Zhai, K.; Wang, J.M. The Silk Road Economic Belt and the 21st Century Maritime Silk Road (2017); The Commercial Press: Beijing, China, 2018

9. Ke, S.Z.; Han, F. A composite measure and statistical estimation of China's urban economic development potentials. Stat. Res. 2013, 3, 64-71.

10. Ruda, A.; Pokladníková, M. Map agebra in tourism potential modelling for improving social issues in Masaryk's school forest enterprise Křtiny. Geogr. Tech. 2016, 11, 67-83. [CrossRef]

11. Nestoroska, I. Identifying tourism potentials in Republic of Macedonia through regional approach. Procedia-Soc. Behav. Sci. 2012, 44, 95-103. [CrossRef] 
12. Wang, S.J.; Xie, J.; Yue, Z.L. China's glacier tourism: Potential evaluation and spatial planning. J. Destin. Mark. Manag. 2020, 18, 1-10. [CrossRef]

13. Trukhachev, A. Methodology for evaluating the rural tourism potentials: A tool to ensure sustainable development of rural settlements. Sustainability 2015, 7, 3052-3070. [CrossRef]

14. Elliot, S.; Papadopoulos, N.; Kim, S.S. An integrative model of place image: Exploring relationships between destination, product, and country images. J. Travel Res. 2011, 50, 520-534. [CrossRef]

15. Andrades, L.; Dimanche, F. Destination competitiveness and tourism development in Russia: Issues and challenges. Tour. Manag. 2017, 62, 360-376. [CrossRef]

16. Crettaz, U. Marketing im fremdenverkehr. Tour. Rev. 1976, 31, 12-15. [CrossRef]

17. Corneliu, L.; Mihai, B. A critical analysis on the evaluation of tourism attractiveness in Romania. Case study: The region of Moldavia. In Proceedings of the 5th WSEAS International Conference on Economy and Management Transformation, Timisoara, Romania, 24 October 2010; pp. 145-150.

18. Glavan, V. Tourist Potential and Its Capitalization; Fundației România de Mâine: Bucharest, Romania, 1996.

19. Mamun, A.A.; Mitra, S. A methodology for assessing tourism potential:Case study murshidabad district, West Bengal, India. Int. J. Sci. Res. Publ. 2012, 2, 1-8.

20. Havlíková, M.; Stupková, L.C.; Plíšková, L. Evaluation of sustainable tourism potential of the principle Giant Mountains resorts in the Czech Republic. Environ. Socio-Econ. Stud. 2019, 7, 26-35. [CrossRef]

21. Shohan, R.; Toleuuly, A.; Assadova, Z.K. Tourist potential and prospects of tourism industry of Kazakhstan. Educ. Sci. Board. 2012, 5, 34-37.

22. Ma, Y.; Dong, G.Z. The sustainable development potential model of regional tourism industry. Tour. Trib. 1997, 4, 37-40.

23. Yang, M. The develop potential of tourism industry in Qinghai province. J. Stat. Decis. 2006, 14, 42-44.

24. Wang, Z.F. The construction of systematic index of developing potential competence in regional tourism industry. East China Econ. Manag. 2008, 10, 31-35.

25. Qin, Y.C.; Wang, X.; Lu, X.Q.; Li, Z.G.; Chen, S.M. The problems of coordination for regional sustainable development: (I) Concept and objectives. J. Henan Univ. 1997, 12, 77-83.

26. Qin, Y.C.; Xu, M.J.; Wang, X. On the constraints of the potential of investor output on the process of regional sustainable development. J. Quant. Tech. Econ. 2001, 1,36-38.

27. Lu, F.X.; Qin, Y.C.; Xu, L.S.; Meng, H. Tourism ecological footprint-A case study of Songshan Scenic Spot in Maylst Golden Week of 2005. Hum. Geogr. 2006, 10, 31-35.

28. Zhu, H.; Liu, J.M.; Wei, Z.C.; Li, W.H.; Wang, L. Residents' attitudes towards sustainable tourism development in a historical-cultural village: Influence of perceived impacts, sense of place and tourism development potential. Sustainability 2017, 9, 61. [CrossRef]

29. Melián-González, A.; García-Falcón, J.M. Competitive potential of tourism in destinations. Ann. Tour. Res. 2003, 30, 720-740. [CrossRef]

30. Crampon, L.J. A new technique to analyze tourist markets. J. Mark. 1966, 30, 27-31. [CrossRef]

31. Bao, J.G. An application of gravity model in tourist forecasting. Acta Sci. Nat. Univ. Sunyatseni 1992, 31, $133-136$.

32. Wilson, S.; Fesenmaier, D.R.; Fesenmaier, J.; Van Es, J.C. Factors for success in rural tourism development. J. Travel Res. 2001, 40, 132-138. [CrossRef]

33. Tian, L.; Tang, X.X.; Wang, J. Dynamics Measure of Regional Tourism Development Potential—A Case Study of 16 City in Yunnan Province. Resour. Dev. Mark. 2017, 33, 738-743.

34. Cao, X.X. A comparison study on the development potential of transprovincial tourism industry in China. Hum. Geogr. 2007, 22, $18-22$.

35. Song, Y.M. Study on the evaluation and display mechanism of regional tourism industry development potential: Take Shaanxi as an example. Ph.D. Thesis, Shaanxi Normal University, Xi'an, China, 2013.

36. Zhang, Z.L.; Liang, L.K. The spatial-temporal evolution and spatial correlation analysis of urban tourism development potential in Henan Province. J. Luoyang Norm. Univ. 2018, 10, 17-23.

37. Wu, C.B. Quantitative research on the potentiality of urban tourism development-Taking the open coastal cities in China as an example. Tour. Forum 2009, 10, 685-694.

38. Ding, J.J.; Zhu, Q.H. Study on Spatial-temporal Differences of Development Potential of Regional Tourism Industry in China. Tour. Trib. 2012, 2, 52-61.

39. Yu, Q.Y. Research on the Potential of Tourism Industry in China. Ph.D. Thesis, East China Normal University, Shanghai, China, 2010.

40. González-Ramiro, A.; Gonçalves, G.; Sánchez-Ríos, A.; Jeong, J.S. Using a VGI and GIS-Based Multicriteria Approach for Assessing the Potential of Rural Tourism in Extremadura (Spain). Sustainability 2016, 8, 1144. [CrossRef]

41. Li, H. Preliminary study of the preserve tourism protection-Based on the theory of ecological footprint. For. Econ. 2005, 7, 43-45.

42. Santana-Gallego, M.; Ledesma-Rodríguez, F.; Pérez-Rodríguez, J. The euro effect: Tourism creation, tourism diversion and tourism potential within the European Union. Eur. Union Politics 2016, 17, 46-68. [CrossRef]

43. Jarábková, J. The rural areas—the unutilized potential in light of tourism. Agric. Econ. 2010, 56, 532-539. [CrossRef]

44. Khodadadi, M. Donald Trump, US foreign policy and potential impacts on Iran's tourism industry: Post-nuclear deal. Tour. Mangement Perspect. 2018, 26, 28-30. [CrossRef] 
45. Li, L.P. The stripping and integrating study of heritage community—historical and cultural villages: Culture tourism sustainable development. Ph.D. Thesis, Northwest University, Lanzhou, China, 2008.

46. Feng, H.H.; Chen, X.P.; Heck, P.; Miao, H. An Entropy-Perspective Study on the Sustainable Development Potential of Tourism Destination Ecosystem in Dunhuang, China. Sustainability 2014, 6, 8980-9006. [CrossRef]

47. Hoang, H.T.T.; Truong, Q.H.; Nguyen, A.T.; Hens, L. Multicriteria evaluation of tourism potential in the central highlands of Vietnam: Combining Geographic Information System (GIS), Analytic Hierarchy Process (AHP) and Principal Component Analysis (PCA). Sustainability 2018, 10, 3097. [CrossRef]

48. Dwyer, L.; Kim, C.W. Destination competitiveness: Determinants and indicators. Curr. Issues Tour. 2003, 6, 369-414. [CrossRef]

49. Chen, Y.; Jiang, B.; Chu, N.C.; Cui, S.L.; Lu, J.B. A study on the measurement of tourism supply and demand potential in Northeast China by High-Speed Railway. Railw. Transp. Econ. 2019, 10, 14-22.

50. Matei, F.D. Cultural tourism potential, as part of rural tourism development in the North-East of Romania. Procedia Econ. Financ. 2015, 23, 453-460. [CrossRef]

51. Wozniak, E.; Kulczyk, S.; Derek, M. From intrinsic to service potential: An approach to assess tourism landscape potential. Landsc. Urban Plan. 2017, 170, 209-220. [CrossRef]

52. Zhou, L.Z.; Zhou, G.M.; Ying, M. Analysis of suitable climate indicators for tourism activities. Meteorol. Sci. Technol. 1998, 1, 60-63.

53. Sun, G.N.; Ma, L.J. An analysis of tourist climate comfortable degree and yearly variation of tourist traffic in Xi'an. Tour. Trib. 2007, 7, 34-39.

54. Lubowiecki-Vikuk, A.; Kurkowiak, J. Medical tourism potential of central and eastern Europe: Attempt at classification. In Proceedings of the CBU International Conference on Innovations in Science and Education, Prague, Czech Republic, 22-24 March 2017; pp. 286-293.

55. Sai, N. "Internet Plus" allows ecotour tourism potential to be released at an accelerated pace. People's Trib. 2016, 12, 90-91.

56. Martín Martín, J.M.; Salinas Fernández, J.A.; Rodríguez Martín, J.A.; Jiménez Aguilera, J.D.D. Assessment of the tourism's potential as a sustainable development instrument in terms of annual stability: Application to Spanish rural destinations in process of consolidation. Sustainability 2017, 9, 1692. [CrossRef]

57. Cui, Y.; Xi, J.C. Market classification analysis of China provincial outbound tourism based on the travel potential model. Resour. Sci. 2015, 37, 2120-2128.

58. Lu, X.J.; Zhou, C.H.; Zhang, H.Y.; Xu, Z.G. Analytical scheme on scale-structure of geographical space. Prog. Geogr. 2004, 3, 107-114.

59. Dube, K.; Nhamo, G. Evidence and impact of climate change on South African national parks. Potential implications for tourism in the Kruger National Park. Environ. Dev. 2020, 33, 100485. [CrossRef]

60. Li, Z.M.; Zou, H.X.; Yi, Q.Q.; Zhou, Q. The agricultural cultural heritage tourism resources potential evaluation to terraces. Econ. Geogr. 2015, 6, 198-208.

61. Radovanov, B.; Dudic, B.; Gregus, M.; Marcikic Horvat, A.; Karovic, V. Using a two-stage DEA model to measure tourism potentials of EU countries and Western Balkan countries: An approach to sustainable development. Sustainability 2020, $12,4903$. [CrossRef]

62. Kelly, N.; Kelliher, F.; Power, J.; Lynch, P. Unlocking the niche potential of senior tourism through micro-firm owner-manager adaptive capability development. Tour. Manag. 2020, 79, 104081. [CrossRef]

63. Yan, L.B.; Gao, B.W.; Zhang, M. A mathematical model for tourism potential assessment. Tour. Manag. 2017, 63, 355-365. [CrossRef]

64. Li, Y.P.; Lo, R.L.B. Applicability of the market appeal—robusticity matrix: A case study of heritage tourism. Tour. Manag. 2004, 25, 789-800. [CrossRef]

65. iReaserch. 2016 China Online Travel Platform White Paper. Available online: https://www.baidu.com/link?url=-wTBPN7 HmzM0wbb3YkQMCXCAK0zl-cfkiYLSH1d6nsts6gZd2Plxeo9g0WdraMfEsjAeqSgQDd7LzdH60Q00V-fJ2q9ZZNDBpf6 Dkbp8WuEpi41YzLyZSewnKXGNp1Fo\&wd=\&eqid=ef8c7c52002a6f2a00000003610d75ce (accessed on 7 August 2021).

66. Qin, X.; Zhen, F.; Zhu, S.J.; Xi, G.L. Spatial pattern of catering industry in Nanjing urban area based on the degree of public praise from internet: A case study of Dianping.com. Sci. Geogr. Sin. 2014, 7, 810-817.

67. Puška, A.; Pamucar, D.; Stojanović, I.; Cavallaro, F.; Kaklauskas, A.; Mardani, A. Examination of the sustainable rural tourism potential of the Brčko District of Bosnia and Herzegovina using a fuzzy approach based on group decision making. Sustainability 2021, 13, 583. [CrossRef]

68. The State Council of China. Guidance on the Promotion of the Development of All-for-One Tourism. Available online: http: / / zwgk.mct.gov.cn/zfxxgkml/zykf/202012/t20201213_919358.html (accessed on 22 March 2018).

69. Baidu Encyclopedia. All-for-One Tourism. Available online: https://baike.baidu.com/item/\%E5\%85\%A8\%E5\%9F\%9F\%E6\%9 7\%85\%E6\%B8\%B8/2987065?fr=aladdin (accessed on 23 May 2018).

70. China Daily. All-for-one tourism. Available online: http://www.chinadaily.com.cn/opinion/2017-03/09/content_28486265.htm (accessed on 9 March 2017).

71. Calderón-Vargas, F.; Asmat-Campos, D.; Carretero-Gómez, A. Sustainable tourism and renewable energy: Binomial for local development in Cocachimba, Amazonas, Peru. Sustainability 2019, 11, 4891. [CrossRef] 